\title{
Shaping Attitudes Across Realities. Exploring Strategies for the Design of Persuasive Virtual, Augmented and Mixed Reality Games
}

\author{
Martijn J.L. Kors ${ }^{1,2\left({ }^{\star}\right)}$, Karel Millenaar ${ }^{2}$, Erik D. van der Spek $^{1}$, Gabriele Ferri ${ }^{2}$, Ben \\ A.M. Schouten ${ }^{1,2}$ and Tim Marsh ${ }^{3}$ \\ ${ }^{1}$ Eindhoven University of Technology, Industrial Design, the Netherlands \\ \{m.j.l.kors, e.d.vanderspek, bschouten\}@tue.nl \\ ${ }^{2}$ Amsterdam University of Applied Sciences, Play and Civic Media, the Netherlands \\ \{m.j.l.kors, k.millenaar, g.ferri, b.a.m.schouten\}@hva.nl \\ ${ }^{3}$ Griffith Film School and Queensland College of Art, Australia \\ t.marshegriffith.edu.au
}

\begin{abstract}
Virtual, Augmented and Mixed Reality technologies are embraced by designers, scholars and charities alike, some primarily for their entertaining properties, others also for the opportunities in education, motivation or persuasion. Applications with the latter objective, that of persuasion, are designed not only to be entertaining, but also hold the intent to shape how players think and feel about issues in reality. However, despite the growing interest in the persuasive opportunities of these immersive technologies, we are at the very forefront and still lack the design strategies and best-practices that could support in the design of these 'immersive persuasive games'. To address this still-unexplored and fragmented design space we organize a design-oriented workshop that brings together academia and industry. The workshop is informed by a Research through Design approach in which the primary focus is to generate knowledge through designing. Participants design and evaluate ideas on-thespot in an iterative manner using low-fidelity, life-size, prototyping and roleplaying techniques, thereby mimicking an embodied interactive immersive environment. By reflecting on design practices and player experiences we construct a body of knowledge, built exemplar work and distill best-practices to formulate design strategies for the design of immersive persuasive games.
\end{abstract}

\section{Towards Immersive Persuasive Games}

It took well over two decades for Virtual Reality to make a commercial comeback after its backlash in the late eighties / early nineties. And even though its future is still uncertain, many have already embraced the new wave of Virtual Reality technologies for various objectives, among which persuasion. Similarly uncertain in its outlook, but not less interesting, we see an increasing proliferation of consumer-grade Augmented Reality devices, such as mobile phones, Google Glass and Microsoft HoloLens. Together, these new or resurgent technologies blur the boundaries of the magic circle. They place you virtually inside the body of another person, or change the 
world around you to reflect another person (or fictional character)'s reality. The experiences in these alternate reality devices can be designed not only to be entertaining, but also hold the intent to shape how players think and feel about issues in their own reality [6].

As we playfully interact with this alternate reality, thus we engage in gameplay, experientially gleaning meaning from this digitally enhanced virtual or augmented world. Bogost pointed at the unique persuasive properties of digital games in general, coining the term 'procedural rhetoric'. Procedural rhetoric, in Bogost's words, is seen as "the art of persuasion through rule-based representations and interactions rather than the spoken word, writing, images or moving pictures" [1]. Through rules and procedures, the way simulations play out, games can covertly present players with enthymemes framed to tell something about issues in their own reality. A classic example of such a Persuasive Game is 'Darfur is Dying', a game that "was created in 2006 to put you [the player] in the shoes of a displaced Darfurian refugee” [10] to have the player experience 'what it feels like' to be a refugee, shape her attitudes, and hopefully stimulate to take action in the real world. Looking at the contemporary media landscape there is probably no other field in which questions of empathy and persuasion play a more vibrant role than in that of immersive technologies. Through these technologies it has become significantly easier to immerse the player in a virtual world, creating a sense of presence, and have her stand in someone else's shoes $[4,6]$. Artists like Milk have already dubbed Virtual Reality the "ultimate empathy machine" [8], and the salience of this topic is further illustrated by recent Virtual and Mixed Reality projects like Project Syria, DeathTolls Experience, and one of our own projects, A Breathtaking Journey [6]. These projects are all designed with the intent to, just like 'Darfur is Dying' over a decade ago, raise empathy and shape attitudes towards refugees by placing the player in their shoes. The idea of placing the player in someone else's shoes relates to concept of role-playing, perspective taking and directexperience, which have shown to support persuasion [7]. However, despite the captivating persuasive potential of immersive technologies [2], we unfortunately still lack the design know-how to advance the design of these immersive persuasive games. This workshop is organized to address this gap in design knowledge. Through a Research through Design inspired approach [14], participants design and evaluate ideas on-the-spot in an iterative manner [3]. We focus on low-fidelity, life-size, prototyping and role-playing techniques, thereby mimicking a Mixed Reality environment without having to rely on technical implementation during the workshop. By reflecting on design practices and player experiences we construct a body of knowledge, collect exemplar work and distill best-practices that to help in formulating design strategies.

\section{Workshop planning}

The workshop will be held as a single-day event, and is expected to host approximately 12 participants. We will distribute the call for papers through social media, industry platforms, mailing lists, special interest groups and the workshop's website. We will also invite experts of exemplar work to join and share their perspective. The following table presents a preliminary planning for the workshop. 


\begin{tabular}{|c|l|}
\hline Time & \multicolumn{1}{|c|}{ Activity } \\
\hline 09:00-11:00 & $\begin{array}{l}\text { PechaKucha. After a short introduction by the organizers we ask each participant to } \\
\text { present their PechaKucha presentation [5] based on their submitted abstract, with } \\
\text { particular focus on design related factors. After each presentation we will shortly } \\
\text { recap the highlighted design opportunities or issues, which will serve as input for the } \\
\text { initial ideation and prototyping session. }\end{array}$ \\
\hline $11: 00-12: 00$ & $\begin{array}{l}\text { Initial Ideation. After dividing the group in teams of 4 participants we will explain } \\
\text { the persuasive message as starting point for their game; including several background } \\
\text { stories and a set of persuasive game design 'lenses' (an adaptation on the Game De- } \\
\text { sign Lenses [11]). Teams then explore the topic, frame possible arguments, set player } \\
\text { experience goals [3] and have a first through about suitable gameplay possibilities. }\end{array}$ \\
\hline $12: 00-13: 00$ & $\begin{array}{l}\text { Lunch Break. } \\
\text { 13:30-17:00 } \\
\text { Prototyping. In the third session each team will have four hours to iteratively [3] } \\
\text { work on their prototype using techniques like Bodystorming [12]. Each teams is asked } \\
\text { to create a low-fidelity, life-size, prototype using the provided material and tools (e.g. } \\
\text { large foam blocks and foam cutters). This setup will mimic an immersive and embod- } \\
\text { ied interactive Mixed Reality environment, without the need to rely on technical } \\
\text { implementation. Throughout we will intervene with Role-playing techniques [13] to } \\
\text { evaluate player experience. During these interventions the team will act as the game's } \\
\text { mechanics, while someone from another team acts as the player. As informed by a } \\
\text { Research through Design approach [14] we will discuss and document interesting, } \\
\text { unexpected and valuable insights throughout the design process for later reflection. }\end{array}$ \\
\hline $\begin{array}{l}\text { Defining Design Insights. In the fourth session we will discuss the insights and for- } \\
\text { mulate possible strategies, techniques and best-practices that were supportive for the } \\
\text { ideation and prototyping processes. }\end{array}$ \\
\hline $17: 00-18: 00$
\end{tabular}

\section{Expected Workshop Outcomes}

All accepted submission will be included in the workshop proceedings that are accessible through the workshop's website. After the workshop we will share a summary of the workshop; including a collection of the formulated design strategies and best-practices for later reference, as well as an overview of the prototypes that can serve as exemplar work. After the workshop we also invite authors to submit a casebased design-oriented abstract for review to be included in the Persuasive Gaming in Context book, funded by the Netherlands Organization for Scientific Research [9].

\section{$4 \quad$ Primary Workshop Organizers}

Martijn J L Kors is a doctoral candidate and game designer at the Eindhoven University of Technology and Amsterdam University of Applied Sciences. In his design-research he studies the design of immersive interactive entertainment for attitude change.

Karel Millenaar is an experienced game designer who supports research as a designer and lecturer at the Amsterdam University of Applied Sciences. He also founded FourceLabs, a company that designs serious games for attitude and behavior change. 


\section{Submissions}

Submissions should be a maximum of 4 pages long in Springer LNCS format (including references), addressing one or more of the following topics. (non-academic design-based submission are also welcome, and should include a detailed description of a persuasive Augmented, Virtual Reality or Mixed Reality game).

- Design or analysis of immersive, persuasive games, techniques, prototypes and concepts.

- Persuasive game design strategies, approaches, techniques or best-practices.

- Interviews, experimental or ethnographic studies on the development of immersive persuasive games.

Articles need to be submitted before the 9th of June 2017, and will be reviewed based on their relevance, quality and contribution to the workshop.

\section{References}

1. Bogost, I.: Persuasive games: The expressive power of videogames. Mit Press (2007).

2. Carpenter, J.M., Green, M.C.: Flying with Icarus: narrative transportation and the persuasiveness of entertainment. Psychology of entertainment media, 2nd edn. Routledge, Florence. 169-194 (2012).

3. Fullerton, T.: Game Design Workshop: A Playcentric Approach to Creating Innovative Games. CRC Press (2008).

4. Grigorovici, D.: Persuasive Effects of Presence in Immersive Virtual Environments. In G. Riva, F. Davide, \& W. IJsselsteijn (Eds.), Being there: Concepts, effects and measurement of presence in synthetic environments. (2003).

5. Klein, A., Dytham, M.: PechaKucha 20x20, http://www.pechakucha.org.

6. Kors, M.J.L. et al.: A Breathtaking Journey. On the Design of an Empathy-Arousing MixedReality Game. In: Proceedings of the 2016 Annual Symposium on Computer-Human Interaction in Play. pp. 91-104 ACM (2016).

7. Maio, G., Haddock, G.: The psychology of attitudes and attitude change. Sage (2009).

8. Milk, C.: How virtual reality can create the ultimate empathy machine. TED (2015).

9. Netherlands Organisation for Scientific Research: Persuasive gaming. From theory-based design to validation and back, http://www.nwo.nl/en/research-and-results/researchprojects/i/76/10476.html.

10. Ruiz, S. et al.: Darfur is dying. (2006).

11. Schell, J.: The Art of Game Design: A Deck of Lenses, Second Edition. Schell Games (2014)

12. Schleicher, D. et al.: Bodystorming As Embodied Designing. Interactions. 17, 6, 47-51 (2010).

13. Simsarian, K.T.: Take It to the Next Stage: The Roles of Role Playing in the Design Process. In: CHI '03 Extended Abstracts on Human Factors in Computing Systems. pp. 1012-1013 ACM, New York, NY, USA (2003).

14. Zimmerman, J. et al.: Research through design as a method for interaction design research in HCI. In: Proceedings of the SIGCHI Conference on Human Factors in Computing Systems. pp. 493-502 ACM (2007). 